УДК 004.942

Олег Васильович Боровик (доктор технічних наук, професор)

Людмила Володимирівна Боровик (доктор педагогічних наук, доцент) Олександр Васильович Андрушко

Національна академія Державної прикордонної служби Украӥни ім. Б. Хмельницького, Украӥна

\title{
УДОСКОНАЛЕННЯ НАУКОВО-МЕТОДИЧНОГО АПАРАТУ РОЗПІЗНАВАННЯ РІВНЯ НЕБЕЗПЕКИ СИТУАЦІЙ У РАЗІ ЗМІНИ ХАРАКТЕРИСТИК ІНФОРМОВАНОСТІ ОСОБИ, ЯКА ПРИЙМАЄ РІШЕННЯ
}

Дослідження системних задач розпізнавання рівня небезпеки ситуачій $i$ запобігання критичним ситуаціям у складних системах різного призначення є актуальним завданням. Це пояснюється тим, шо часткове або повне руйнування таких систем спричиняе не лише катастрофічні наслідки для них самих, а и призводить до суттєвих збитків, які часто перевищують вартість самих систем. Останні можуть бути як матеріальними, так $і$ не матеріальними. Аналіз ряду катастроф у різних галузях людськоі діяльності, свідчить про те, щзо масштаби втрат можуть бути значно меншими, якщо в позаштатній ситуації вчасно сформувати $і$ реалізувати раціональні рішення. Одним із можливих підходів до розв'язання задач розпізнавання та запобігання критичним ситуаціям у складних системах, є підхід, що базується на реалізації механізмів корегування показників інформованості особи, яка приймає рімення.

У роботі здійснено формалізацію задачі підвищення достовірності даних щзодо визначення допустимого періоду часу на формування і реалізацію рішення, для якого ймовірність переходу певної ситуачії в критичну, надзвичайну або катастрофічну не перевищуватиме заданого значення, а також класифікації та розпізнавання рівня небезпеки ситуацій. Також проведено аналіз існуючого підходу щзодо вирішення сформульованої задачі у випадку застосування механістичного підходу визначення кількісних показників інформованості особи, яка приймає рімення, що дозволило виявити проблемні питання, які мають місие при його застосуванні. На основі застосування системи аналогій запропоновано підхід щзодо підвищення ефективності розв'язування подібних задач і програмно-алгоритмічне забезпечення його реалізаиіï.

Зазначений підхід базується на встановленні переліку причин, які обумовлюють фактори, ще можуть випливати на зміну ситуаџій досліджуваної системи, їх ваги, варіантів впливу причин на появу фактора, та на основі иъього уточнення показника достовірності інформованості особи, яка приймає рішення. Він також може застосовуватись для підвищення точності оцінки й інших кількісних показників інформованості особи, зокрема повноти та своєчасності.

Програмно-алгоритмічна реалізачія авторського підходу до вирімення досліджуваної задачі дозволяє автоматизувати окремі етапи вирішення задачі та покращити рівень об'єктивності розв'язків.

Ключові слова: математична модель; критична ситуачія; особа, яка приймає рімення; інформованість; достовірність; фактори; причини; експертна оцінка; матриці; алгоритм; програмне забезпечення.

\section{Вступ}

Необхідність дослідження системних задач розпізнавання і запобігання позаштатним, критичним і катастрофічним ситуаціям у складних системах різного призначення (технічних, організаційних тощо) безпосередньо випливає 3 тенденцій та особливостей їх розвитку. Адже часткове або повне руйнування таких систем спричиняє не лише катастрофічні наслідки для них самих, а й призводить до суттєвих збитків, які часто перевищують вартість самих систем. Такі збитки можуть бути як матеріальними, так і не матеріальними (наприклад, іміджевими, політичними, безпековими). Аналіз ряду катастроф у різних галузях людської діяльності, що проведений авторами, свідчить про те, що масштаби втрат можуть бути значно меншими, якщо в позаштатній ситуації вчасно сформувати i реалізувати раціональні рішення.

Постановка проблеми. На даний час у системному аналізі існують методи, які дозволяють 3 певною точністю розв'язувати ці задачі. Вони базуються на застосуванні показників інформованості особи, яка приймає рішення (ОПР). Такі показники в межах дослідження приймаються заданими. Однак результати розв'язків у ряді випадків свідчать про їх незадовільний рівень. Саме тому актуальним $є$ завдання пошуку підходів до розв'язання задач розпізнавання та запобігання позаштатним, критичним i катастрофічним ситуаціям у складних системах різного призначення, які б забезпечували достатній рівень 
об'єктивності розв'язків.

Під час формалізації і розв’язування реальних задач $з$ описаного вище класу важливе значення мають якісні характеристики використовуваної інформації [1].

Зважаючи на це, одним із можливих підходів до розв'язання задач розпізнавання та запобігання позаштатним, критичним i катастрофічним ситуаціям у складних системах різного призначення, який би забезпечував достатній рівень об'єктивності розв'язків, $є$ підхід, що базується на реалізації механізмів корегування показників інформованості ОПР у межах встановленого на початковому етапі періоду часу та динамічного уточнення тривалості самого періоду.

Таким чином, проблемну задачу, яка потребує вирішення, можна сформулювати так.

У процесі функціонування певної системи під впливом множини неконтрольованих факторів ризику деяка штатна ситуація може перейти в критичну, надзвичайну або катастрофічну. Такий перехід може відбуватися упродовж деякого періоду часу, тривалість якого апріорі невідома, i який залежить від кількості, властивостей i тривалості впливу факторів. Потрібно визначити такий допустимий період часу на формування i реалізацію рішення, для якого ймовірність переходу ситуації в критичну, надзвичайну або катастрофічну не перевищуватиме задане значення, i який би забезпечував достатній рівень об'єктивності розв'язків.

Аналіз остатніх досліджень і публікацій. Зважаючи на підхід, який пропонується для розв'язання визначеної задачі, актуальним $\epsilon$ проведення аналізу існуючих підходів щодо оцінювання інформації у контексті задачі формування рішень.

Одним із найбільш поширених підходів $є$ підхід, що базується на застосуванні показників оцінювання кількості інформації. Він описаний у працях Шеннона [2], Колмогорова [3], Кульбака [4]. Подальший розвиток цього підходу пов'язується 3 роботою основоположника кібернетики Н. Вінера [5]. Поставлені кібернетикою якісно нові проблеми, пред'явили нові вимоги до формування вихідної інформації. Одним із основних результатів робіт [2-5] стали запропоновані А. Н. Колмогоровим нові ідеї визначення кількості інформації, на основі яких були розроблені нові підходи: комбінаторний i алгоритмічний.

Однак у працях [2-5] не оцінювалися такі показники якості інформації, як повнота, достовірність, своєчасність. Зважаючи ж на те, що вирішення ряду прикладних системних задач потребувало урахування не лише кількості інформації, а й ऑiі якісних характеристик, у наступних роботах науковці почали приділяти увагу цьому аспекту. Саме цим пояснюється той факт, що окремі дослідники пропонували методи перетворення якісних характеристик в кількісні, та подальшу обробку отриманих характеристик звичними для математиків методами. Такий підхід мав місце для фінансової галузі та відповідних прикладних задач.

У сучасній теорії інформаційного аналізу заслуговують на увагу методи та підходи, які відображені в роботі Річарда Грінольда та Рональда Кана з Каліфорнійського університету в Берклі [1], яка містить цікаві ідеї щодо формалізації процесу відбору корисної фінансової інформації для формування інвестиційного портфелю. В роботі наведені не тільки теоретичні відомості та загальна математична постановка задачі, а й результати досліджень та застосування запропонованих методів в американських фінансових компаніях. Також автори навели основні переваги й недоліки запропонованих ними методологій, описали основні принципи вибору правильних джерел інформації та методів оцінки їх релевантності.

Розвиток цих ідей знайшов відображення в роботах [6-11], які стосувалися економічних аспектів діяльності, та у працях [12-15], в яких були досліджені інформаційні аспекти забезпечення прийняття рішень в інших галузях людської діяльності.

Незважаючи на достатньо великий перелік наукових праць, які стосуються досліджуваної задачі, на сьогодні ще не до кінця сформовано універсальний підхід, який би дозволяв розв'язувати іiі, забезпечуючи при цьому достатній рівень об'єктивності рішення.

Метою статті $\epsilon$ удосконалення науковометодичного апарату розпізнавання та запобігання позаштатним, критичним i катастрофічним ситуаціям у складних системах різного призначення.

\section{Виклад основного матеріалу дослідження}

Для досягнення мети вбачається за доцільне: здійснити формалізацію досліджуваної задачі; здійснити аналіз існуючого підходу щодо ï вирішення; окреслити коло проблемних питань, що мають місце при його застосуванні; запропонувати механізм реалізації власного підходу щодо вирішення досліджуваної задачі; сформувати програмно-алгоритмічне забезпечення його реалізації.

Математична постановка задачі.

Нехай у процесі функціонування складно керованої системи під впливом множини $\Phi=\left\{\Phi_{\mathrm{j}} \mid \mathrm{j}=\overline{1, \mathrm{n}}\right\} \quad$ неконтрольованих факторів ризику $\Phi_{\mathrm{j}}$ штатна ситуація $\mathrm{S}_{\mathrm{i}}(\mathrm{i}=\overline{1, \mathrm{~m}})$ може перейти в критичну, надзвичайну або катастрофічну. Такий перехід може відбуватися упродовж деякого періоду часу, тривалість якого невідома, і який залежить від кількості, властивостей i тривалості впливу (табл. 1) факторів $\Phi_{\mathrm{j}} \in \Phi$.

Потрібно визначити такий допустимий період часу $\mathrm{T}_{0}$ на формування і реалізацію рішення, для 
якого ймовірність переходу ситуації $\mathrm{S}_{\mathrm{i}}$ в критичну, надзвичайну або катастрофічну не перевищуватиме задане значення $\eta=\eta_{д о п ~}$ (тобто визначити допустимий період часу на формування і реалізацію рішення, що запобігає катастрофічній ситуації), а також класифікувати та розпізнати рівень небезпеки ситуацій (тобто встановити чи є ситуація критичною, чи вона надзвичайна, чи катастрофічна).

Тут під критичною ситуацією розуміється позаштатний режим функціонування, за якого показники якості системи або показники зовнішнього середовища лежать поза інтервалами штатного режиму в таких межах, що виникає реальна загроза аварії або катастрофи. Аварійна ситуація - позаштатний режим функціонування, за якого система переходить із дієздатного стану в такий недієздатний, аварійний стан, що для переходу у вихідний стан необхідно здійснити певні впливи (наприклад, для технічних систем виконати певні ремонтні роботи). Тут аварія - це кінцевий результат аварійної ситуації. Катастрофічна ситуація - позаштатний режим функціонування, за якого система переходить із дієздатного стану в такий недієздатний, катастрофічний стан, що перехід у початковий стан принципово виключений. Тут катастрофа це кінцевий результат катастрофічної ситуації.

Таблиця 1

\begin{tabular}{|c|c|c|c|c|}
\hline \multirow{2}{*}{$\begin{array}{c}\text { Найменування } \\
\text { ситуації } \mathrm{S}_{\mathrm{i}}\end{array}$} & \multicolumn{4}{|c|}{$\begin{array}{c}\text { Неконтрольовані фактори ризику } \\
\Phi_{\mathrm{j}} \in \Phi, \text { що впливають на } \\
\text { ситуацію }\end{array}$} \\
\cline { 2 - 5 } & $\Phi_{1}$ & $\Phi_{2}$ & $\cdots$ & $\Phi_{\mathrm{n}}$ \\
\hline $\mathrm{S}_{1}$ & + або - & + або - & $\ldots$ & + або - \\
\hline $\mathrm{S}_{2}$ & + або - & + або - & $\ldots$ & + або - \\
\hline$\ldots$ & $\ldots$ & $\ldots$ & $\ldots$ & $\ldots$ \\
\hline $\mathrm{S}_{\mathrm{m}}$ & + або - & + або - & $\ldots$ & + або - \\
\hline $\mathrm{y}$
\end{tabular}
відповідного фактора штатна ситуація переходить у критичну, надзвичайну або катастрофічну, а знак «-» - фактор ризику не впливає на ситуацію.

Аналіз існуючого підходу щодо вирішення досліджуваної задачі.

Розглянемо насамперед першу частину задачі, що стосується визначення періоду часу $\mathrm{T}_{0}$. Базовий метод іiі вирішення описаний у роботі [12]. Згідно цього методу насамперед необхідно розрахувати допоміжні коефіцієнти $\alpha_{\mathrm{ij}}, \beta_{\mathrm{ij}}, \gamma_{\mathrm{ij}}$, що характеризують динаміку змін показників інформованості. Ці коефіцієнти знаходяться за формулами [12]:

$$
\begin{aligned}
& \alpha_{i j}=\left\{\begin{array}{c}
e^{\hat{\alpha}_{i j}} \hat{I}_{\Pi}^{\mathrm{ij}} 0,5, \text { якщо } 0<\hat{\alpha}_{\mathrm{ij}} \leq 1, \\
0, \quad \text { якщо } \hat{\alpha}_{\mathrm{ij}}>1 ;
\end{array}\right. \\
& \beta_{\mathrm{ij}}=\left\{\begin{array}{c}
\left.\left(\hat{\alpha}_{\mathrm{ij}}+\gamma_{\mathrm{ij}}\right)\right)_{\mathrm{T}}^{\mathrm{ij}} 10^{-5}, \text { якщо } 0<\hat{\alpha}_{\mathrm{ij}}+\gamma_{\mathrm{ij}} \leq 1, \\
0, \quad \text { якщо } \hat{\alpha}_{\mathrm{ij}}>1 ;
\end{array}\right.
\end{aligned}
$$

$$
\gamma_{\mathrm{ij}}=\left\{\begin{array}{c}
\mathrm{e}^{\hat{\mathrm{I}}_{\mathrm{D}}^{\mathrm{ij}}} \hat{\alpha}_{\mathrm{ij}} 0,05, \text { якщо } 0<\hat{\alpha}_{\mathrm{ij}} \leq 1, \\
0, \quad \text { якщо } \hat{\alpha}_{\mathrm{ij}}>1 .
\end{array}\right.
$$

У виразах (1)-(3) $\hat{\alpha}_{i j}$ - коефіцієнт, що характеризує рівень впливу кожного 3 факторів $\Phi_{\mathrm{j}} \in \Phi$ на властивості ситуації $\mathrm{S}_{\mathrm{i}}: \hat{\alpha}_{\mathrm{ij}} \in[0 ; 1] \mathrm{i}$ визначається експертно. А $\hat{\mathrm{I}}_{Д}^{\mathrm{ij}}, \hat{\mathrm{I}}_{\Pi}^{\mathrm{ij}}, \hat{\mathrm{I}}_{\mathrm{T}}^{\mathrm{ij}}-$ це попередні оцінки показників $\mathrm{I}_{Д}^{\mathrm{ij}}, \mathrm{I}_{\Pi}^{\mathrm{ij}}, \mathrm{I}_{\mathrm{T}}^{\mathrm{ij}}$, які визначаються в момент виявлення позаштатного режиму функціонування системи: $\hat{\mathrm{I}}_{Д}^{\mathrm{ij}}, \hat{\mathrm{I}}_{\Pi}^{\mathrm{ij}}, \hat{\mathrm{I}}_{\mathrm{T}}^{\mathrm{ij}} \in[0 ; 1]$ і також визначаються експертно. Самі ж показники $\mathrm{I}_{Д}^{\mathrm{ij}}, \mathrm{I}_{\Pi}^{\mathrm{ij}}, \mathrm{I}_{\mathrm{T}}^{\mathrm{ij}}$ - це показники, що характеризують достовірність, повноту, своєчасність інформованості ОПР про вплив факторів $\Phi_{\mathrm{j}} \in \Phi$ на властивості ситуації $\mathrm{S}_{\mathrm{i}}$. Їх відшукання здійснюється так:

$$
\begin{aligned}
& \mathrm{I}_{Д}^{\mathrm{ij}}(\mathrm{t})=\left\{\begin{array}{cc}
\hat{\mathrm{I}}_{Д}^{\mathrm{ij}}\left(1+\gamma_{\mathrm{ij}} \mathrm{t}\right), & \text { якщо } 0<\hat{\mathrm{I}}_{Д}^{\mathrm{ij}}\left(1+\gamma_{\mathrm{ij}} \mathrm{t}\right)<1, \\
1, & \text { якщо } \hat{\mathrm{I}}_{Д}^{\mathrm{ij}}\left(1+\gamma_{\mathrm{ij}} \mathrm{t}\right) \geq 1 ;
\end{array}\right. \\
& \mathrm{I}_{\Pi}^{\mathrm{ij}}(\mathrm{t})=\left\{\begin{array}{cc}
\hat{\mathrm{I}}_{\Pi}^{\mathrm{ij}}\left(1+\alpha_{\mathrm{ij}} \mathrm{t}\right), \text { якщо } 0<\hat{\mathrm{I}}_{\Pi}^{\mathrm{ij}}\left(1+\alpha_{\mathrm{ij}} \mathrm{t}\right)<1, \\
1, & \text { якщо } \hat{\mathrm{I}}_{\Pi}^{\mathrm{ij}}\left(1+\alpha_{\mathrm{ij}} \mathrm{t}\right) \geq 1 ;
\end{array}\right. \\
& \mathrm{I}_{\mathrm{T}}^{\mathrm{ij}}(\mathrm{t})=\left\{\begin{array}{cc}
\hat{\mathrm{I}}_{\mathrm{T}}^{\mathrm{ij}}\left(1-\beta_{\mathrm{ij}} \mathrm{t}^{2}\right), \text { якщо } 0<\beta_{\mathrm{ij}} \mathrm{t}^{2}<1, \\
0, & \text { якщо } \beta_{\mathrm{ij}} \mathrm{t}^{2} \geq 1 .
\end{array}\right.
\end{aligned}
$$

На основі знання значень показників $\mathrm{I}_{Д}^{\mathrm{ij}}, \mathrm{I}_{\Pi}^{\mathrm{ij}}, \mathrm{I}_{\mathrm{T}}^{\mathrm{ij}}$ знаходиться значення інтегрального показника інформованості у фіксований момент часу $\mathrm{t}$ за співвідношенням

$$
I_{i j}(t)=I_{\Pi}^{i j}(t) I_{T}^{i j}(t) I_{Д}^{i j}(t) .
$$

При його відшуканні слід враховувати наступне:

1. Рівень інформованості зростає безперервно від збільшення кожного $з$ показників $\mathrm{I}_{\Pi}, \mathrm{I}_{\mathrm{T}}, \mathrm{I}_{Д}$ або тільки одного з них.

2. Загальний рівень інформованості у разі збільшення його повноти, достовірності і своєчасності підвищується за нелінійним законом, a саме: приріст рівня інформованості поступово сповільнюється в міру наближення показників повноти, достовірності і своєчасності до їх граничних значень.

3. Рівень інтегрального показника інформованості у разі зменшення значення одного 3 показників нижче від деякого граничного значення не може бути компенсований за рахунок збільшення значень інших показників.

4. За нульового значення будь-якого 3 показників $\mathrm{I}_{П}, \mathrm{I}_{\mathrm{T}}, \mathrm{I}_{\text {Д }}$ загальний рівень інформованості також дорівнює нулю.

Далі знаходиться ймовірність переходу ситуації $\mathrm{S}_{\mathrm{i}}$ у критичну під впливом фактору $\Phi_{\mathrm{j}} \in \Phi$ у вигляді 


$$
\eta_{\mathrm{ij}}(\mathrm{t})=1-\lg \left[1+\alpha_{\mathrm{ij}} \mathrm{I}_{\mathrm{ij}}(\mathrm{t})\right] .
$$

Після цього для визначення тривалості допустимого періоду $\mathrm{T}_{0}$ розв'язується нерівність:

$$
\begin{aligned}
& 0 \leq 1-\lg \left(1+\alpha_{\mathrm{ij}}{ }_{\mathrm{T}}^{\mathrm{ij}} \mathrm{I}_{\Pi}^{\mathrm{ij}} \mathrm{I}_{\text {Д }}^{\mathrm{ij}} \times\right. \\
& \left.\times\left(1+\alpha_{\mathrm{ij}} \mathrm{t}\right)\left(1+\gamma_{\mathrm{ij}} \mathrm{t}\right)\left(1-\beta_{\mathrm{ij}} \mathrm{t}^{2}\right)\right) \leq \eta_{\text {доп }} .
\end{aligned}
$$

Результатом розв'язання нерівності (9) проміжок $\left[\mathrm{T}_{1} ; \mathrm{T}_{2}\right]$.

Слід зауважити, що проміжки $\left[\mathrm{T}_{1} ; \mathrm{T}_{2}\right]$ знаходяться для всіх активних пар $(\mathrm{i} ; \mathrm{j})$, що визначаються наявними факторами $\Phi_{j} \in \Phi$ та можливими ситуаціями $\mathrm{S}_{\mathrm{i}}$. Тоді величина $\mathrm{T}_{0} \in\left[0 ; \overline{\mathrm{T}}_{2}\right]$, де $\overline{\mathrm{T}}_{2}$ рівне мінімальному із значень $\mathrm{T}_{2}$ тих проміжків $\left[\mathrm{T}_{1} ; \mathrm{T}_{2}\right]$, які характерні для різних факторів $\Phi_{\mathrm{j}} \in \Phi$ для конкретної ситуації $\mathrm{S}_{\mathrm{i}}$. Тобто тривалість $\mathrm{T}_{0}$ не може перевищувати величини $\overline{\mathrm{T}}_{2}$.

Початковою умовою для другої частини досліджуваної задачі $є$ проміжок $\left[\mathrm{T}^{-} ; \mathrm{T}^{+}\right]$, який визначає класифікацію ситуацій $\mathrm{S}_{\mathrm{i}}$ щодо їх критичності. Так, якщо для ситуації $\mathrm{S}_{\mathrm{i}}$ іiї значення $\mathrm{T}_{0}$ таке, що $\mathrm{T}_{0} \leq \mathrm{T}^{-}$, то ситуація $\mathrm{S}_{\mathrm{i}}$ відноситься до класу катастрофічних ситуацій. Якщо $\mathrm{T}_{0} \in\left(\mathrm{T}^{-} ; \mathrm{T}^{+}\right)$, то ситуація $\mathrm{S}_{\mathrm{i}}$ відноситься до класу надзвичайних ситуацій. Якщо ж $\mathrm{T}_{0}>\mathrm{T}^{+}$, то ситуація $\mathrm{S}_{\mathrm{i}}$ відноситься до класу критичних ситуацій. Межі проміжку $\left\lfloor\mathrm{T}^{-} ; \mathrm{T}^{+}\right\rfloor$ встановлюються емпірично i можуть бути нечіткими.

Вирішення другої частини досліджуваної задачі передбачає встановлення для кожної ситуації $S_{i}$ такого часового проміжку $\left\lfloor\mathrm{T}_{\mathrm{S}_{\mathrm{i}}}^{-} ; \mathrm{T}_{\mathrm{S}_{\mathrm{i}}}^{+}\right\rfloor$, в якому $\mathrm{T}_{\mathrm{S}_{\mathrm{i}}}^{-}=\min _{\mathrm{j}}^{-} \mathrm{i} \mathrm{T}_{\mathrm{S}_{\mathrm{i}}}^{+}=\max _{\mathrm{j}}^{+}, \mathrm{a} \mathrm{T}_{\mathrm{j}}^{-}, \mathrm{T}_{\mathrm{j}}^{+}$- це значення, які знаходяться для кожного фактора $\Phi_{\mathrm{j}} \in \Phi$, що є активними для фіксованої ситуації $\mathrm{S}_{\mathrm{i}}, 3$ нерівності [12]

$$
\begin{aligned}
& \eta^{-} \leq 1-\log _{2}\left(1+\alpha_{i j} I_{T}^{i j} I_{\Pi}^{i j} I_{-}^{i j} \times\right. \\
& \left.\times\left(1+\alpha_{i j} t\right)\left(1+\gamma_{i j} t\right)\left(1-\beta_{i j} t^{2}\right)\right) \leq \eta^{+} .
\end{aligned}
$$

У нерівності (10) $\eta^{-}, \eta^{+}$- це допустимі межі ймовірності переходу кожної ситуації $\mathrm{S}_{\mathrm{i}}$ в критичну, надзвичайну або катастрофічну за всіма факторами $\Phi_{\mathrm{j}} \in \Phi$.

Далі для кожної ситуації $\mathrm{S}_{\mathrm{i}}$ визначається місце розташування ii інтервалу $\left\lfloor\mathrm{T}_{\mathrm{S}_{\mathrm{i}}}^{-} ; \mathrm{T}_{\mathrm{S}_{\mathrm{i}}}^{+}\right\rfloor$на інтервалі $\left\lfloor\mathrm{T}^{-} ; \mathrm{T}^{+}\right\rfloor$. Це дозволяє класифікувати всі ситуації $S_{i}$ щодо їх критичності.
Проблемні питання, що мають місце при застосуванні існуючого підходу щодо вирішення досліджуваної задачі.

Аналіз алгоритму існуючого підходу щодо вирішення досліджуваної задачі, який наведений вище, дозволяє зробити висновок про те, що існують проблемні питання щодо ефективності існуючого методу. До числа таких відносяться наступні:

1. При розрахунку допоміжних коефіцієнтів $\alpha_{\mathrm{ij}}, \beta_{\mathrm{ij}}, \gamma_{\mathrm{ij}}$, які характеризують динаміку змін показників інформованості, доводиться оперувати значеннями коефіцієнта $\hat{\alpha}_{\mathrm{ij}}$ та показників $\hat{\mathrm{I}}_{\text {Д }}^{\mathrm{ij}}, \hat{\mathrm{I}}_{\Pi}^{\mathrm{ij}}, \hat{\mathrm{I}}_{\mathrm{T}}^{\mathrm{ij}}$, що встановлюються за попередніми оцінками експертів, які можуть виявитися досить наближеними та неякісне встановлення яких може вплинути на об'єктивність розв'язків.

2. Технологія встановлення значень коефіцієнта $\hat{\alpha}_{\mathrm{ij}}$ та показників $\hat{\mathrm{I}}_{Д}^{\mathrm{ij}}, \hat{\mathrm{I}}_{\Pi}^{\mathrm{ij}}, \hat{\mathrm{I}}_{\mathrm{T}}^{\mathrm{ij}}$ може загалом впливати на збільшення періоду $\mathrm{T}_{0}$, що може змінити критичність ситуації.

Таким чином, фактор достовірності результатів i оперативності щодо формування рішення обумовлюють необхідність аналізу механізмів щодо їх забезпечення.

Авторський механізм удосконалення існуючого підходу щодо вирішення досліджуваної задачі.

Авторське бачення механізмів удосконалення існуючого підходу щодо вирішення досліджуваної задачі стосується удосконалення процедури встановлення значення показника $\hat{\mathrm{I}}_{\text {Д }}^{\mathrm{ij}}$ Суть удосконалення полягає в наступному.

Кожен 3 факторів ризику $\Phi_{j} \in \Phi$, які можуть впливати на зміну критичності ситуації $\mathrm{S}_{\mathrm{i}}$, може мати місце за ряду причин $\mathrm{P}_{\mathrm{k}}$ фізичного характеру. При цьому, перелік і кількість причин для кожного 3 факторів $\Phi_{\mathrm{j}} \in \Phi$ може бути різною. Тому позначимо причини, що впливають на появу фактора $\Phi_{\mathrm{j}} \in \Phi$, як $\mathrm{P}_{\mathrm{jk}}$. Тут $\mathrm{k}_{\mathrm{j}}$ - це кількість причин, які впливають на появу фактора саме $\Phi_{\mathrm{j}} \in \Phi$.

Слід зауважити, що вага кожної з причин $\mathrm{P}_{\mathrm{jk}}$, які впливають на появу фактора $\Phi_{\mathrm{j}} \in \Phi$, може бути різною. Позначимо іiі як $\alpha_{j k_{j}}$. Отже, $\alpha_{j k_{j}}$ це вага причини $P_{\mathrm{jk}_{\mathrm{j}}}$ активності фактора $\Phi_{\mathrm{j}} \in \Phi$.

Слід зазначити і те, що за наявності впливу фактора $\Phi_{j} \in \Phi$ на різні ситуації $S_{i}$ (тобто при наявності знака «+» у відповідній клітинці табл. 1) комбінація причин $\mathrm{P}_{\mathrm{jk}}$, які обумовлюють такий вплив на конкретну ситуацію $\mathrm{S}_{\mathrm{i}}$, може бути різною. Більше того, варіант впливу причини на появу фактора також може бути різним. Позначимо його так: $\mathrm{V}_{\mathrm{jk}} \mathrm{j}$. . Отже, $\mathrm{V}_{\mathrm{jk}}$. $\mathrm{i}$ - це 
варіант впливу причини $\mathrm{P}_{\mathrm{jk}_{\mathrm{j}}}$ на появу фактора $\Phi_{\mathrm{j}} \in \Phi$, якщо він впливає на можливість зміни ситуації $\mathrm{S}_{\mathrm{i}}$.

При цьому, варіанти впливу причин на фактор можуть бути такими: причина безпосередньо впливає на появу фактора (БВ); причина має суттєвий вплив на появу фактора (CB); причина має вплив на появу фактора (B); причина має незначний вплив на появу фактора (НВ).

3 урахуванням наведеного, початкову умову задачі щодо встановлення значення показника $\hat{\mathrm{I}}_{\text {Д }}^{\mathrm{ij}}$ можна представити у вигляді табл. 2.

Сама ж задача полягає у тому, щоб 3 урахуванням даних табл. 2 знайти значення показника $\hat{\mathrm{I}}_{\text {Д }}^{\mathrm{ij}}$.

3 урахуванням теорії, що описана у праці [16], та стосується питань оцінки ефективності математичних моделей, загалом, та достовірності результатів моделювання, зокрема, 3 великим ступенем точності можна стверджувати, що для визначення величин $\mathrm{V}_{\mathrm{jk}}$.i можна скористатися описаним у вказаній роботі підходом. Згідно цього підходу та з урахуванням системи аналогій,

$$
\mathrm{V}_{\mathrm{jk} . \mathrm{i}}=\left\{\begin{array}{c}
0, \text { якщо має місце БВ; } \\
0445, \text { якщо має місце БВ; } \\
0.6, \text { якщо має місце БВ; } \\
1.33, \text { якщо має місце БВ. }
\end{array}\right.
$$

Оскільки основним змістом вимоги щодо достовірності результатів моделювання $\epsilon$ достатньо точне відображення найбільш суттєвих сторін процесів, що моделюються і притаманних їм закономірностей, то для оцінки величини $\hat{\mathrm{I}}_{Д}^{\mathrm{ij}}$ слід обов'язково приймати до уваги перелік і характер впливу причин $\mathrm{P}_{\mathrm{jk}_{\mathrm{j}}}$ на появу фактора $\Phi_{\mathrm{j}} \in \Phi$, якщо він впливає на можливість зміни ситуації $\mathrm{S}_{\mathrm{i}}$.

За відсутності детальної моделі досліджуваної задачі значення важливості $\alpha_{\mathrm{jk}_{\mathrm{j}}}$ причин $\mathrm{P}_{\mathrm{jk}}$ можуть бути оцінені експертно завчасно (до початку змін ситуаціі).

Тоді показник $\hat{\mathrm{I}}_{\text {Д }}^{\mathrm{ij}}$ з урахуванням впливу кожної з причин на появу фактора для фіксованої ситуації може бути визначений так:

$$
\hat{\mathrm{I}}_{\text {Д }}^{\mathrm{ij}}=1-\sum_{\mathrm{k}_{\mathrm{j}}}\left(\mathrm{V}_{\mathrm{jk}_{\mathrm{j}} \mathrm{i}} \cdot \alpha_{\mathrm{jk}_{\mathrm{j}}}\right) .
$$

У (12) коефіцієнт $\alpha_{\mathrm{jk}_{\mathrm{j}}}$ відображає вагу причини у відносних одиницях, визначену на основі оцінки усіх причин за стобальною шкалою експертною комісією. А значення $\mathrm{V}_{\mathrm{jk}}$.i визначає похибку, що вноситься в розрахунки внаслідок неточного (узагальненого) врахування впливу причин.
Застосування формули (12) вирішує задачу у здійсненій постановці.

\begin{tabular}{|c|c|c|c|c|c|}
\hline $\begin{array}{c}\text { Перелік } \\
\text { причин } \\
\mathrm{P}_{\mathrm{jk}} \text {, що }\end{array}$ & $\begin{array}{c}\text { Вага } \alpha_{j k_{j}} \\
\text { причини } \\
P_{i k} .\end{array}$ & $\begin{array}{r}\text { Найме } \\
\text { впли }\end{array}$ & $\begin{array}{r}\text { ування } \\
\text { на яку } \\
\Phi_{\mathrm{j}} \in\end{array}$ & $\mathrm{Ia} \in \mathrm{c}$ & $\begin{array}{l}\text { ації } \mathrm{S}_{\mathrm{i}} \text {, } \\
\text { актор }\end{array}$ \\
\hline $\begin{array}{c}\text { впливають } \\
\text { на появу } \\
\text { фактора } \\
\Phi_{\mathrm{j}} \in \Phi\end{array}$ & $\begin{array}{c}\text { активності } \\
\text { фактора } \\
\Phi_{\mathrm{j}} \in \Phi\end{array}$ & $\mathrm{S}_{1}$ & $\mathrm{~S}_{2}$ & $\ldots$ & $\mathrm{S}_{\mathrm{m}}$ \\
\hline$P_{j 1}$ & $\alpha_{j 1}$ & $\mathrm{~V}_{\mathrm{j} 1.1}$ & $\mathrm{~V}_{\mathrm{j} 1.2}$ & $\ldots$ & $\mathrm{V}_{\mathrm{j} 1 . \mathrm{m}}$ \\
\hline$P_{j 2}$ & $\alpha_{j 2}$ & $\mathrm{~V}_{\mathrm{j} 2.1}$ & $\mathrm{~V}_{\mathrm{j} 2.2}$ & $\cdots$ & $\mathrm{V}_{\mathrm{j} 2 . \mathrm{m}}$ \\
\hline$\ldots$ & $\ldots$ & $\ldots$ & $\ldots$ & $\ldots$ & $\ldots$ \\
\hline$P_{j k_{j}}$ & $\alpha_{j k_{j}}$ & $\mathrm{~V}_{\mathrm{jk} \mathrm{j}_{\mathrm{j}} 1}$ & $\mathrm{~V}_{\mathrm{jk}} .2$ & $\ldots$ & $\mathrm{V}_{\mathrm{jk}} \cdot \mathrm{m}$ \\
\hline
\end{tabular}

Таблиця 2

3 урахуванням наведеного, удосконалений алгоритм розв'язування початкової задачі може мати наступний вигляд:

1. Формується табл. 1.

2. Формується шаблон табл. 2.

3. Проводиться розрахунок i встановлення даних табл. 2.

4. Формується матриця даних показника $\hat{\mathrm{I}}_{Д}^{\mathrm{ij}}$ на основі застосування виразів (11)-(12).

5. Експертно встановлюються матриці даних показників $\hat{\mathrm{I}}_{\Pi}^{\mathrm{ij}}, \hat{\mathrm{I}}_{\mathrm{T}}^{\mathrm{ij}}$ і матриці коефіцієнтів $\hat{\alpha}_{\mathrm{ij}}$.

6. Проводиться розрахунок матриці коефіцієнтів $\gamma_{\mathrm{ij}}$ на основі застосування формули (3).

7. Проводиться розрахунок матриць коефіціснтів $\alpha_{\mathrm{ij}}, \beta_{\mathrm{ij}}$ на основі застосування формул (1)-(2).

8. На основі застосування формул (4)-(6) проводиться розрахунок значень показників $\mathrm{I}_{\text {Д }}^{\mathrm{ij}}, \mathrm{I}_{\Pi}^{\mathrm{ij}}, \mathrm{I}_{\mathrm{T}}^{\mathrm{ij}}$.

9. Застосовується формула (7) для відшукання значення інтегрального показника інформованості у фіксований момент часу $\mathrm{t}$.

10. Знаходиться ймовірність переходу ситуації $S_{i}$ у критичну під впливом фактору $\Phi_{\mathrm{j}} \in \Phi$ на основі застосування формули (8).

11. На основі розв'язування нерівності (9) знаходяться проміжки $\left[\mathrm{T}_{1} ; \mathrm{T}_{2}\right]$ для кожної активної пари $(\mathrm{i} ; \mathrm{j})$.

12.3 урахуванням описаного вище підходу знаходиться тривалість $\mathrm{T}_{0}$.

13. Проводиться класифікація всіх ситуацій $\mathrm{S}_{\mathrm{i}}$ щодо їх критичності на основі застосування формули (10).

Запропонований підхід до визначення показника $\hat{\mathrm{I}}_{\text {Дj }}^{\mathrm{ij}}$ разі його автоматизації дозволяє одночасно усунути проблемні аспекти, що мають місце при застосуванні існуючого підходу щодо вирішення досліджуваної задачі.

Таким чином, актуальним $є$ завдання формування програмного забезпечення реалізації 
наведеного удосконаленого алгоритму.

Програмно-алгоритмічне забезпечення реалізації авторського механізму удосконалення існуючого підходу щодо вирішення досліджуваної задачі.

Для реалізації наведеного алгоритму було реалізовано відповідний програмний додаток. Серверна частина додатку виконана в середовищі Node.js iз застосуванням бази даних MongoDB. Вибір середовища зумовлений швидкодією при операціях введення-виведення та роботи 3 даними [17-20].

Фрагмент реалізації додатку, що стосується наведеного алгоритму, наведений нижче.

import mongoose from "mongoose";

import_from "lodash";

Calculator.methods $=$ \{calculateAlpha $(\mathrm{i}, \mathrm{j}$ ) \{const alphaCircumflex = this.alphaCircumflexMatrix[i][j];

if (!alphaCircumflex) \{

return null;

\}

return this.alphaCircumflexMatrix[i][j] $>1$

$? 0$

Math.exp(alphaCircumflex)

this.IpCircumflexMatrix $[\mathrm{i}][\mathrm{j}] * 0.5$;

\},

calculateBeta(i, j) \{

const alpha $=$ this.calculateAlpha $(\mathrm{i}, \mathrm{j})$;

if (!alpha) \{

return null;

\}

const gamma $=$ this.calculateGamma(i, $\mathrm{j})$;

if (alpha + gamma $>=1)\{$

return 0 ;

\}

return (alpha + gamma)

this.ItCircumflexMatrix[i][j] * Math.pow(10, -4);

\},

calculateGamma(i, j)

const alphaCircumflex

this.alphaCircumflexMatrix[i][j];

if (!alphaCircumflex) \{ return null;

\}

if (alphaCircumflex $>1)\{$

return 0 ;

\}

const IdCircumflexMatrix

this.calculateIdCircumflexMatrix();

return Math.exp(IdCircumflexMatrix[i][j]) *

alphaCircumflex *0.05;

\},

calculateIp(i, j, t) \{

const IpCircumflex $=$ this.IpCircumflexMatrix $[\mathrm{i}][\mathrm{j}]$;

if (!IpCircumflex) \{

return null;

\}

const result $=$ IpCircumflex $*(1+$

this.calculateAlpha $(\mathrm{i}, \mathrm{j}) * \mathrm{t})$;

return result $>=1$ ? 1 : result;

\} ,

...calculateAcceptablePeriod(i, j, etaAcceptable) \{

const deltaT $=0.1$

let $\mathrm{t}=0$,

polynome,

TValues $=[]$;

do \{

polynome $=$ this acceptablePeriodPolynome $(\mathrm{i}, \mathrm{j}, \mathrm{t})$;

if ( polynome $==$ null) \{

return null;

\}

TValues.push( $\{t$, polynome $\})$;

$\mathrm{t}+=$ deltaT;

\} while (polynome $>=0$ );

TValues $=$ TValues.filter $(\mathrm{x} \Rightarrow$ x.polynome $<=$ etaAcceptable);

TValues $=$ TValues.map $(x=>$ x.t $)$;

return__.max(TValues) ?

parseFloat(_.max(TValues).toFixed(2))] : null; \},

Результати роботи додатку, що опрацьований авторами та відповідає наведеному методу, можуть бути оцінені з рис. 1-4.

\section{Дані для визначення $\hat{i ̂ j}_{\text {म }}$ Чинники для фактора $\Phi_{1}$}

\begin{tabular}{|c|c|c|c|c|c|}
\hline \multirow{2}{*}{$\begin{array}{l}\text { Перелік } \\
\text { причин } \boldsymbol{P}_{j k} \text {, } \\
\text { що } \\
\text { впливають } \\
\text { на появу } \\
\text { фактора } \\
\phi_{j} \in \phi\end{array}$} & \multirow{2}{*}{$\begin{array}{l}\text { Вага } \alpha_{j k_{j}} \\
\text { причини } P_{j k_{j}} \\
\text { активності } \\
\text { фактора } \\
\phi_{j} \in \Phi\end{array}$} & \multicolumn{4}{|c|}{ Найменування ситуації $S_{i}$, вплив на яку має фактор $\phi_{j} \in \phi$} \\
\hline & & $\mathbf{s}_{1}$ & $\mathbf{s}_{2}$ & $\mathbf{S}_{3}$ & $\mathbf{S}_{4}$ \\
\hline P1.1 & 0.1 & B & $\mathrm{CB}$ & B & CB \\
\hline P1.2 & 0.2 & CB & CB & B & $\mathrm{HB}$ \\
\hline P1.3 & 0.2 & CB & CB & $\mathrm{HB}$ & $\mathrm{HB}$ \\
\hline P1.4 & 0.2 & $\mathrm{HB}$ & B & B & CB \\
\hline P1.5 & 0.15 & $\mathrm{HB}$ & B & CB & $\mathrm{HB}$ \\
\hline P1.6 & 0.15 & БB & CB & БB & $\mathrm{HB}$ \\
\hline
\end{tabular}




\section{Чинники для фактора $\Phi_{2}$}

\begin{tabular}{|c|c|c|c|c|c|}
\hline \multirow{2}{*}{$\begin{array}{l}\text { Перелік } \\
\text { причин } \boldsymbol{P}_{j k_{j}} \text {, } \\
\text { що } \\
\text { впливають } \\
\text { на появу } \\
\text { фактора } \\
\phi_{j} \in \Phi\end{array}$} & \multirow{2}{*}{$\begin{array}{l}\text { Вага } \alpha_{j k_{j}} \\
\text { причини } P_{j k_{j}} \\
\text { активності } \\
\text { фактора } \\
\phi_{j} \in \Phi\end{array}$} & \multicolumn{4}{|c|}{ Найменування ситуації $S_{i}$, вплив на яку має фактор $\phi_{j} \in \phi$} \\
\hline & & $\mathbf{s}_{1}$ & $s_{2}$ & $\mathbf{S}_{3}$ & $s_{4}$ \\
\hline P2.1 & 0.5 & $\mathrm{HB}$ & B & БB & $\mathrm{HB}$ \\
\hline $\mathrm{P} 2.2$ & 0.1 & CB & $\mathrm{CB}$ & БB & B \\
\hline P2.3 & 0.1 & CB & $\mathrm{HB}$ & B & БB \\
\hline P2.4 & 0.05 & B & $\mathrm{CB}$ & B & $\mathrm{HB}$ \\
\hline P2.5 & 0.05 & $\mathrm{HB}$ & CB & БB & $\mathrm{HB}$ \\
\hline P2.6 & 0.2 & БB & $\mathrm{CB}$ & B & $\mathrm{HB}$ \\
\hline
\end{tabular}

\section{Чинники для фактора $\Phi_{3}$}

\section{Чинники для фактора $\Phi_{4}$}

Рис. 1. Введення в систему даних для визначення $\hat{\mathrm{I}}_{\text {Дi }}^{\mathrm{ij}}$

$\hat{I}^{i j_{n}}$

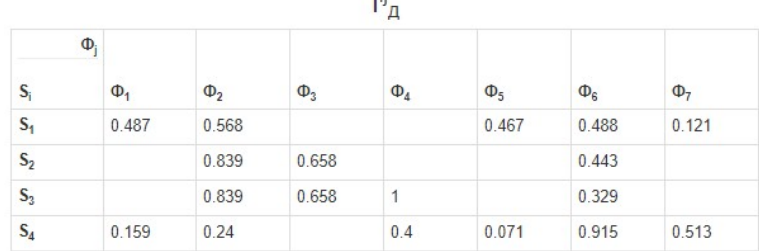

$\mathrm{I}_{\mathrm{g}}(\mathrm{t})$

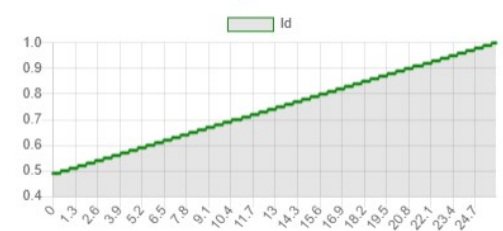

$\hat{i} i_{n}$

\begin{tabular}{|l|l|l|l|l|l|l|l|}
\hline \multicolumn{2}{|c|}{$\Phi_{\mathrm{j}}$} & & & & & & \\
\hline $\mathbf{S}_{\mathrm{i}}$ & $\Phi_{1}$ & $\Phi_{2}$ & $\Phi_{3}$ & $\Phi_{4}$ & $\Phi_{5}$ & $\Phi_{6}$ & $\Phi_{7}$ \\
\hline $\mathbf{S}_{1}$ & 0.6 & 0.7 & & & 0.5 & 0.7 & 0.6 \\
\hline $\mathbf{S}_{2}$ & & 0.5 & 0.5 & & & 0.5 & \\
\hline $\mathbf{S}_{3}$ & & 0.5 & 0.4 & 0.4 & & 0.8 & \\
\hline $\mathbf{S}_{4}$ & 0.5 & 0.5 & & 0.3 & 0.35 & 0.6 & 0.5 \\
\hline
\end{tabular}

$\mathrm{iij}_{\mathrm{T}}$

\begin{tabular}{|l|l|l|l|l|l|l|l|}
\hline \multicolumn{2}{|c|}{$\Phi_{\mathrm{i}}$} & & & & & \\
\hline $\mathbf{S}_{\mathbf{1}}$ & $\Phi_{1}$ & $\Phi_{2}$ & $\Phi_{3}$ & $\Phi_{4}$ & $\Phi_{5}$ & $\Phi_{6}$ & $\Phi_{7}$ \\
\hline $\mathbf{S}_{1}$ & 0.6 & 0.7 & & & 0.5 & 0.7 & 0.6 \\
\hline $\mathbf{S}_{2}$ & & 0.5 & 0.5 & & & 0.5 & \\
\hline $\mathbf{S}_{3}$ & & 0.5 & 0.4 & 0.4 & & 0.8 & \\
\hline $\mathbf{S}_{4}$ & 0.5 & 0.5 & & 0.3 & 0.35 & 0.6 & 0.5 \\
\hline
\end{tabular}

$I_{\Pi}(\mathrm{t})$

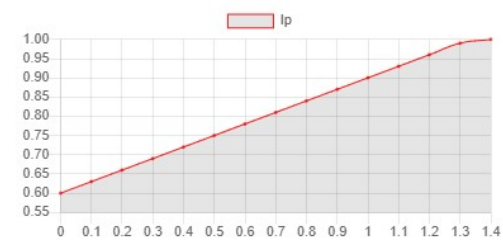

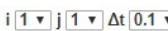

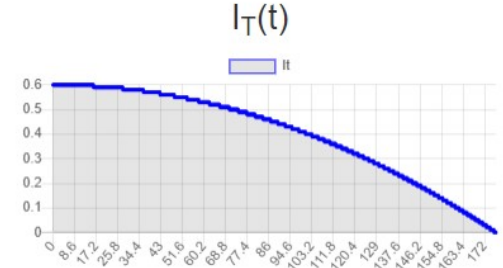

Рис. 2. Інтерфейс введення попередньо визначених показників та відображення результатів обчислення $\mathrm{I}_{\Pi}(\mathrm{t}), \mathrm{I}_{\mathrm{T}}(\mathrm{t}), \mathrm{I}_{\text {Д }}(\mathrm{t}), \widehat{\mathrm{I}}_{\text {Д }}$ з відповідними графіками

$\eta(t)$ $\mathrm{i} 1 \mathrm{j} 1 \mathrm{1} \Delta \mathrm{t} 1$.

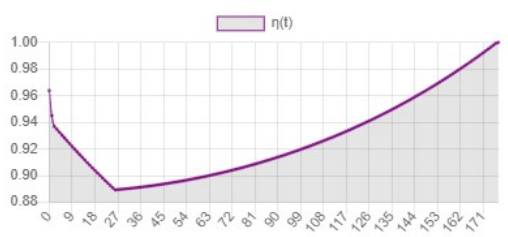

$I(t)$

$\mathrm{i} 1 \mathrm{i} 1 \mathrm{1} \Delta \mathrm{t} 1$

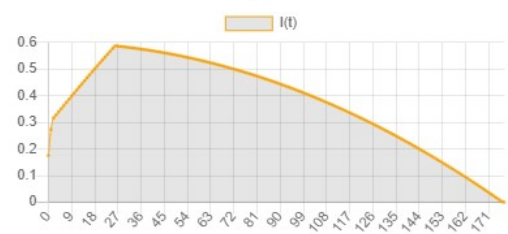

Рис. 3. Інтерфейс побудови графіків функцій інтегрального показника інформованості $\mathrm{I}_{\mathrm{ij}}(\mathrm{t})$ та ймовірностей переходу ситуацій $\eta_{\mathrm{ij}}(\mathrm{t})$ 


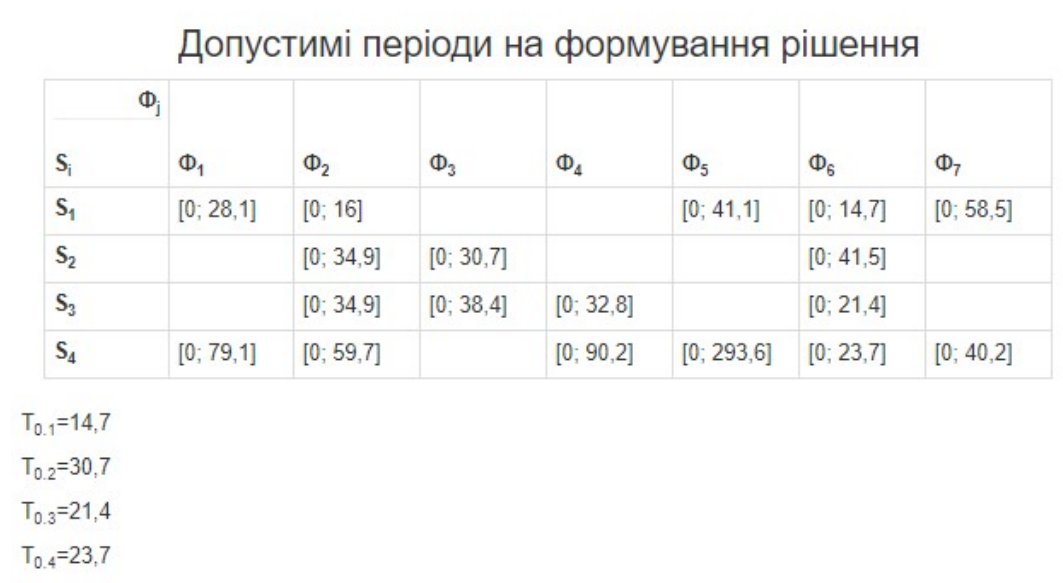

Пдоп 0.8 v

Рис. 4. Інтерфейс відображення результатів визначення допустимих періодів на формування рішення

\section{Висновки й перспективи подальших досліджень}

За результатами проведеного дослідження можна зробити висновок про те, що запропонований підхід щодо корегування показників інформованості ОПР у межах встановленого на початковому етапі періоду часу та динамічного уточнення тривалості самого періоду забезпечує удосконалення науковометодичного апарату вирішення задачі розпізнавання та запобігання позаштатним, критичним і катастрофічним ситуаціям у складних

\section{Лimepamypa}

1. Мазур М. Качественная теория информации. Мир. М. 1972. С. - 239. 2. Колмогоров А. Н. Три подхода к определению понятия «количества информации». Проблемы передачи информации. 1965. Т.1. вып.1. С. 311. 3. Кульбак С. Теория информации и статистика. Наука. М. 1954. С. 376. 4. Колмогоров А. Н. Теория информации и теория алгоритмов. Наука. М.1987. С. 304. 5. Винер Н. Кибернетика или управление и связь в животном и машине. Наука. М. 1983. С. 343. 6. Ілляшенко С. М. Економічний ризик: навчальний посібник. Центр навчальної літератури. 2-ге вид., доп. перероб. К. 2004. С. 220. 7. Шапкин А. С. Экономические и финансовые риски. Оценка, управление, портфель инвестиций: Монография. Изд. Торг. корпорация "Дашков и Ко». М. 2003. С. 5448. Балдин К. В. Информационные системы в экономике: учебник. Издательско-торговая корпорачия «Дашков и Ко». М. 2006. С. 395. 9. Бережной О. А. Інформаційноаналітичне забезпечення прийняття ефективних управлінських рішень. Актуальні проблеми економіки. 2004. №9. С. 26 - 30. 10. Бобруль Г. І. Інформація та інформаційні технології в стратегічному управлінні посередницькою організацією. Актуальні проблеми економіки. 2006. №5. С. 135-143. 11. Волков И. М. системах різного призначення. Слід зауважити, що підхід, який наведений вище i стосується визначення показника $\hat{\mathrm{I}}_{\text {Дj }}^{\mathrm{ij}}$ може бути адаптованим i для відшукання значень матриці коефіцієнтів $\hat{\alpha}_{i j}$, а також встановлення матриць даних показників $\hat{\mathrm{I}}_{\Pi}^{\mathrm{ij}}, \hat{\mathrm{I}}_{\mathrm{T}}^{\mathrm{ij}}$.

Обгрунтування механізмів реалізації наведеної ідеї, а також апробація удосконаленої у роботі моделі на основі конкретного прикладу визначає перспективи подальших досліджень.

Критерии оценки проектов. Институт экономического развития Всемирного банка. М. 2006. С. 128. 12. Згуровський М. 3., Панкратова Н. Д. Основи системного аналізу. Видавнича група ВНV. К. 2007. С 544. 13. Косс В. А. Умови відповідності моделі управління системним потребам об'єкта управління. Математичні машини і системи. 2007. № 1. С. 12-18. 14. Качинський А. В. Засади системного аналізу безпеки складних систем. ДП «HBК «Евроатлантикінформ». К. 2006. С. 336. 15. Gupta J.N.D., Sharma S., Rashid M.A. Handbook of Research on Enterprise Systems. Farmington Hills: Gale Group. 2009. Р. 460. 16. Городнов В. П. Моделирование боевых действий частей, соединений и объединений войск ПВО. Харьков. 1987. С. 383. 17. What is Node.js used for?. Access mode. [Electronic resource]. URL: https: // railsware.com / blog / what-is-node-js-used-for. (date of access: 29.02.2020). 18. Математика в JavaScript. [Electronic resource]. URL: https://habr.com/ru/post/312880 (дата звернення: 29.02.2020). 19. Документация Node.js. URL: https://nodejs.org/ru/docs/ (дата звернення: 29.02.2020). 20. MongoDB Documentation. [Electronic resource]. URL: https://docs.mongodb.com/ (date of access: 29.02.2020).

\section{УСОВЕРШЕНСТВОВАНИЕ НАУЧНО-МЕТОДИЧЕСКОГО АППАРАТА РАСПОЗНАВАНИЯ УРОВНЯ ОПАСНОСТИ СИТУАЦИЙ В СЛУЧАЙ ИЗМЕНЕНИЯ ХАРАКТЕРИСТИК ИНФОРМИРОВАННОСТИ ЛИЦА, ПРИНИМАЮЩЕГО РЕШЕНИЕ}

Олег Васильевич Боровик (доктор технических наук, профессор)

Людмила Владимировна Боровик(доктор педагогических наук, доцент) Александр Васильевич Андруико 
Исследование системных задач распознавания уровня опасности ситуаций и предотвращение критическим ситуация в сложных системах различного назначения является актуальной задачей. Это объясняется тем, что частично или полное разрушение таких систем приводит не лишь катастрофические последствия для них самих, но и производить к существенным убыткам, которые часто превышает стоимость самих систем. Последние могут быть как материальными, так и не материальными. Анализ ряда катастроф в различных областях человеческой деятельности, свидетельствует о том, что масштабы потерь могут быть значительно меньше, если во внештатной ситуации вовремя сформировать и реализовать оптимальные решения. Одним из возможных подходов $\kappa$ решению задач распознавания и предотвращения критических ситуаций в сложных системах, является подход, основанный на реализации механизмов корректировки показателей информированности лица, принимающего ремение.

В работе осуществлено формализачию задачи повыщения достоверности данных по определению допустимого периода времени на формирование и реализацию решения, для которого вероятность перехода определенной ситуации в критическую, чрезвычайную или катастрофическую не превышает заданного значения, а также классификации и распознавания уровня опасности ситуаций. Также проведен анализ существующего подхода к решению сформулированной задачи в случае применения механистического подхода определения количественных показателей информированности лица, принимающего решение, позволивщее выявить проблемные вопросы, имеюшие место при его применении. На основе применения системы аналогий предложен подход по повышению эффективности решения подобных задач и программно-алгоритмическое обеспечение его реализации.

Указанный подход базируется на установлении перечня причин, обуславливающих факторы, которые могут вытекать на смену ситуаций исследуемой системы, их веса, вариантов воздействия причин появления фактора, и на основе этого уточнении показателя достоверности информированности лища, принимающего ремение.

Он также может применяться для повымения точности оценки и других количественных показателей информированности лица, в частности полноты и своевременности.

Программно-алгоритмическая реализаџия авторского подхода к решению исследуемой задачи позволяет автоматизировать отдельные этапь решения задачи и улучшить уровень объективности решений.

Ключевые слова: математическая модель; критическая ситуация; лицо, принимающее решение; информированность; достоверность; факторы; причины; экспертная оценка; матрицы; алгоритм; программное обеспечение.

\title{
IMPROVEMENT OF THE SCIENTIFIC AND METHODOLOGICAL APPARATUS BY RECOGNIZING THE LEVEL OF DANGER OF THE SITUATION IN THE CASE OF CHANGING THE CHARACTERISTICS OF THE INFORMING OF THE DECISION MAKER
}

\author{
Oleh Borovyk (Doctor of Technical Sciences, Professor) \\ Liudmyla Borovyk (Doctor of Science, Associate Professor) \\ Aleksandr Andrushko
}

\section{National Academy of State Border Guard Service of Ukraine named after B. Khmelnytsky, Ukraine}

Research on systemic problems of recognizing the level of danger of situations and preventing critical situations in complex systems of various purposes is an urgent task. This is because the partial or complete destruction of such systems causes not only catastrophic consequences for themselves, but also leads to significant losses that often exceed the cost of the systems themselves. The latter can be both material and nonmaterial. The analysis of a number of catastrophes in different fields of human activity shows that the magnitude of losses can be much smaller if, in an emergency situation, rational decisions are made and implemented in a timely manner. One approach to addressing the challenges of identifying and preventing critical situations in complex systems is an approach based on the implementation of mechanisms for adjusting the awareness of the decision-maker.

The paper formalizes the problem of increasing the reliability of data to determine the permissible time period for the formation and implementation of a solution for which the probability of transition of a certain situation in a critical, emergency or catastrophic will not exceed the set value, as well as the classification and recognition of the level of danger situations. Also, the analysis of the existing approach to solving the formulated problem in the case of applying a mechanistic approach to determining quantitative indicators of the decisionmaker's awareness was made, which revealed the problematic issues that occur in its application. Based on the application of the analogy system, an approach is proposed to improve the efficiency of solving such problems and to provide software and algorithmic support for its implementation.

This approach is based on establishing a list of reasons that determine the factors that may change the situation of the investigated system, their weight, options for the influence of causes on the appearance of the 
factor, and based on this refinement of the confidence indicator of the decision-maker. It can also be used to improve the accuracy of assessment and other quantitative indicators of a person's awareness, including completeness and timeliness.

The algorithmic implementation of the author's approach for solving the problem under study allows you to automate the individual steps of solving the problem and improve the level of objectivity of the solutions.

Keywords: mathematical model; critical situation; decision maker; awareness; reliability; factors; causes; expert judgment; matrices; algorithm; software.

\section{References}

1. Mazur M. Qualitative theory of information [Kachestvennaya teoriya informatsii]. Peace. M. 1972. P. 239. 2. Kolmogorov A. N. Three approaches to the definition of the concept of "amount of information". Problems of information transfer. [Tri podhoda $\mathrm{k}$ opredeleniyu ponyatiya «kolichestva informatsii». Problemyi peredachi informatsii]. 1965. Vol.1. issue 1. Pp. 3-11. 3. Kulbak S. Information theory and statistics. [Teoriya informatsii i statistika] Science. M. 1954. P. 376. 4. Kolmohorov A.N. Information theory and algorithms theory.[Teoriya informatsii i teoriya algoritmov]. Science. M.1987. P. 304. 5.Viner N. Cybernetics or control and communication in animal and machine [Kibernetika ili upravlenie i svyaz v zhivotnom i mashine]. Science. M. 1983. P. 343. 6. Illjashenko S.M. Economic risk: a textbook. Center of Educational Literature [ Ekonomichnyj ryzyk: navchaljnyj posibnyk.].the 2 nd ed., Suppl. republishing. K. 2004. P. 220. 7. Shapkin A.S. Economic and financial risks. Valuation, management, investment portfolio: Monograph. [Ekonomicheskie i finansovyie riski. Otsenka, upravlenie, portfel investitsiy: Monografiya]. Ed. Trade corporation. Dashkov \& Co. Corporation. M. 2003. P. 544. 8. Baldin K.V. Information systems in economics: a textbook. [Informatsionnyie sistemyi $\mathrm{v}$ ekonomike: uchebnik]. Dashkov \& Co. Publishing and Trading Corporation. M. 2006. P. 395. 9. Berezhnoi O.A. Information-analytical support for making effective management decisions [Informacijno-analitychne zabezpechennja pryjnjattja efektyvnykh upravlinsjkykh rishenj]. Actual problems of the economy. 2004. №9. Pp. 26 - 30. 10. Bobrulj Gh. I. Information and informational technologies in the strategic management of an intermediary organization [Informacija ta informacijni tekhnologhiji $\mathrm{v}$ strateghichnomu upravlinni poserednycjkoju orghanizacijeju]. Actual problems of the economy. 2006. №5. Pp. 135-143. 11. Volkov I.M. Criteria for project evaluation [Kriterii otsenki proektov]. World Bank Institute for Economic Development. M. 2006. P. 128. 12. Zghurovsjkyj M. Z., Pankratova N. D. Fundamentals of system analysis [Osnovy systemnogho analizu]. BHV Publishing Group. K. 2007. P. 544. 13. Koss V.A. Conditions for compliance of the management model of the system needs of the management object [Umovy vidpovidnosti modeli upravlinnja systemnym potrebam ob'jekta upravlinnja]. Mathematical Machines and Systems. 2007. № 1. Pp. 12-18. 14. Kachynsjkyj A. V. Fundamentals of system analysis of security of complex systems [Zasady systemnogho analizu bezpeky skladnykh system]. SE «Euroatlantikinform». K. 2006. P. 336. 15. Gupta J.N.D. Sharma S. Rashid M.A. Handbook of Research on Enterprise Systems. Farmington Hills: Gale Group. 2009. P. 460. 16. Gorodnov V.P. Modeling of combat operations of units, formations and unions of air defense forces [Modelirovanie boevyih deystviy chastey, soedineniy i ob'edineniy voysk PVO]. Kharkiv. 1987. P. 383. 17. What is Node.is used for? Access mode. [Electronic resource]. URL: https: // railsware.com / blog / what-is-node-js-used-for. (date of access: 29.02.2020). 18. Math in JavaScript. [Electronic resource]. URL: https://habr.com/post/312880 (accessed 29/02/2020). 19. Node.js documentation URL: https://nodejs.org/en/docs/ (accessed: 02/29/2020). 20. MongoDB Documentation. [Electronic resource]. URL: https://docs.mongodb.com/ (date of access: 29.02.2020). 